\title{
Antiprogestin mifepristone inhibits the growth of cancer cells of reproductive and non-reproductive origin regardless of progesterone receptor expression
}

\author{
Chelsea R Tieszen, Alicia A Goyeneche, BreeAnn N Brandhagen, Casey T Ortbahn and Carlos M Telleria*
}

\begin{abstract}
Background: Mifepristone (MF) has been largely used in reproductive medicine due to its capacity to modulate the progesterone receptor (PR). The study of MF has been expanded to the field of oncology; yet it remains unclear whether the expression of PR is required for MF to act as an anti-cancer agent. Our laboratory has shown that MF is a potent inhibitor of ovarian cancer cell growth. In this study we questioned whether the growth inhibitory properties of MF observed in ovarian cancer cells would translate to other cancers of reproductive and non-reproductive origin and, importantly, whether its efficacy is related to the expression of cognate PR.

Methods: Dose-response experiments were conducted with cancer cell lines of the nervous system, breast, prostate, ovary, and bone. Cultures were exposed to vehicle or increasing concentrations of MF for $72 \mathrm{~h}$ and analysed for cell number and cell cycle traverse, and hypodiploid DNA content characteristic of apoptotic cell death. For all cell lines, expression of steroid hormone receptors upon treatment with vehicle or cytostatic doses of MF for $24 \mathrm{~h}$ was studied by Western blot, whereas the activity of the G1/S regulatory protein Cdk2 in both treatment groups was monitored in vitro by the capacity of Cdk2 to phosphorylate histone $\mathrm{H} 1$.

Results: MF growth inhibited all cancer cell lines regardless of tissue of origin and hormone responsiveness, and reduced the activity of Cdk2. Cancer cells in which MF induced G1 growth arrest were less susceptible to lethality in the presence of high concentrations of MF, when compared to cancer cells that did not accumulate in G1. While all cancer cell lines were growth inhibited by MF, only the breast cancer MCF-7 cells expressed cognate PR.

Conclusions: Antiprogestin MF inhibits the growth of different cancer cell lines with a cytostatic effect at lower concentrations in association with a decline in the activity of the cell cycle regulatory protein Cdk2, and apoptotic lethality at higher doses in association with increased hypodiploid DNA content. Contrary to common opinion, growth inhibition of cancer cells by antiprogestin MF is not dependent upon expression of classical, nuclear PR.
\end{abstract}

\section{Background}

While mifepristone (MF) was originally synthesized as an antiglucocorticoid agent, the realization of its affinity for the progesterone receptor (PR) expanded its study and application in the field of reproductive medicine for early termination of pregnancy, emergency contraception and menstrual cycle regulation [1,2]. More recently, MF emerged as a potential treatment of endocrine-

\footnotetext{
*Correspondence: carlos.telleria@usd.edu

Division of Basic Biomedical Sciences, Sanford School of Medicine of The University of South Dakota, 414 East Clark Street, Vermillion, SD, USA
}

related diseases such as uterine leiomyoma and endometriosis [3]. Moreover, the potential use of MF in oncology has been promising [4]. Because several tumors of both gynecologic and non-gynecologic origin are steroid hormone-dependent and express PR, MF has been investigated as a potential anti-cancer therapeutic agent largely based on its capacity to modulate PR. However, it remains unclear whether the mechanism through which MF acts to induce cytostasis and lethality in cancer cells actually requires PR expression.

\section{() Biomed Central}

(C) 2011 Tieszen et al; licensee BioMed Central Ltd. This is an Open Access article distributed under the terms of the Creative Commons Attribution License (http://creativecommons.org/licenses/by/2.0), which permits unrestricted use, distribution, and reproduction in any medium, provided the original work is properly cited. 
Evidence suggests that the cytostatic effect of MF may be mediated by an agonistic action on PR. Support for this idea comes from studies using T47Dco breast cancer cells expressing high levels of PR, in which MF interfered with cell proliferation, displaying progesterone-like effects [5]. In MDA-MB-231 breast cancer cells that were transfected with $\mathrm{PR}, \mathrm{MF}$, akin to progesterone, inhibited cell growth by arresting cells in the G1 phase of the cell cycle [6]. Conversely, there is also evidence suggesting that the efficacy of MF as an anti-cancer agent may not require PR expression. Liang and colleagues reported that micromolar doses of MF alone were able to inhibit the growth of ER- and PR-negative MDA-MB-231 breast cancer cells [7]. Additionally, MF was capable of inhibiting the growth of $\mathrm{LNCaP}$ prostate cancer cells that were either androgen-sensitive or -refractory [8], while competition for PR and GR with equimolar doses of MF and progesterone or hydrocortisone could not reverse the degree of growth inhibition achieved by MF alone. Furthermore high concentrations of MF were unable to block growth inhibition induced by supra-pharmacological doses of progesterone (i.e. concentrations higher than needed to saturate the cognate PR) in endometrial cancer cells carrying PR [9]; instead high doses of MF potentiated the growth retardation and induction of apoptosis triggered by high doses of progesterone [10]. Such cytotoxicity of elevated concentrations of progesterone and MF was also observed in PR positive MCF-7 breast cancer cells and PR negative C4-I cervical carcinoma cells [11]. These findings imply that MF may be working independently of either cognate PR or GR. On the other hand, competition for GR with an equimolar concentration of dexamethasone partially reversed growth inhibition by MF in the androgen-insensitive PC-3 prostate cancer cells, suggesting a possible role of GR in mediating the growth inhibitory properties of MF [12]. Altogether, findings from reports investigating the anticancer properties of MF as an endocrine-related phenomenon emphasize the lack of clarity regarding whether the mechanistic action of MF involves a specific steroid hormone receptor, although MF is mostly studied for anti-cancer therapy largely based on its anticipated interaction with PR.

In the few existing reports that investigated the effects of MF in epithelial ovarian cancer cells, our laboratory [13-15] and others [16,17], demonstrated the efficacy of MF as a growth inhibitory agent. We have shown that MF inhibits the growth of ovarian cancer cells of different genetic backgrounds in a dose-dependent manner in vitro and in vivo [13]. Our inquiry on the molecular mechanisms underlying MF-induced growth arrest revealed that ovarian cancer cells cultured in the presence of a cytostatic concentration of MF had reduced DNA synthesis and arrested the cell cycle at the G1/S phase transition [13]. Furthermore, exposure of OV2008 and SK-OV-3 ovarian cancer cells to a cytostatic concentration of MF increased the abundance of the cell cycle inhibitors $\mathrm{p} 21^{\mathrm{cip} 1}$ and $\mathrm{p} 27^{\mathrm{kip} 1}$, decreased the abundance of Cdk2 and cyclin E, and decreased Cdk2 activity [13]. These results suggested that the cytostatic effect of MF is mediated through a G1 phase arrest [13]. However, when we exposed 6 different ovarian cancer cell lines of different genetic backgrounds and platinum sensitivities to concentrations of MF higher than $20 \mu \mathrm{M}$, the antiprogestin triggered cell death evidenced by an increase in sub-diploid fragmented DNA content and cleavage of caspase- 3 and of its downstream substrate PARP [14]. Whether MF-mediated growth inhibition in ovarian cancer cells require PR remains unclear. The reported level of expression of $\mathrm{PR}$ in ovarian cancer cell lines is not without controversy. For example, Caov-3 cells were reported to express PR mRNA in one study [18] but not in another [19]. Similarly, studies in SKOV-3 cells showing some or no expression of PR mRNA and protein have been published [19-23].

Up to this point, the literature has not addressed whether MF requires PR expression to work as an anticancer agent. In this study we sought to extend our findings in ovarian cancer cells to cancer cell lines of alternate tissues of origin, including cancers of both reproductive and non-reproductive origin, and questioned whether the expression of PR was related to the sensitivity of the cancer cells to the growth-inhibitory influence of MF. We hypothesized that MF would be capable of growth-inhibiting cancers of reproductive and non-reproductive origin regardless of PR expression, displaying cytostatic effects at lower micromolar concentrations and lethal effects at higher micromolar doses. We describe that MF inhibited the growth of 10 different cancer cell lines originating from the nervous system, breast, prostate, ovary, and bone, of which only one expressed cognate $\mathrm{PR}$, suggesting that contrary to common opinion, the capability of MF to act as a growth inhibitory agent is unrelated to the expression of classical, nuclear PR.

\section{Methods}

\section{Cell lines and in vitro exposure to MF}

The human malignant meningioma IOMM-Lee cells were kindly provided by Dr. Anita Lal (University of California, San Francisco), the human malignant glioma U87MG cells, human osteosarcoma U-2OS and SAOS-2 cells, and estrogen-unresponsive breast carcinoma MDAMB-231 cells were from the American Type Culture Collection (ATCC, Manassas, VA). These cell lines were maintained in Dulbecco's Modification of Eagle's Medium (DMEM) (Mediatech, Herndon, VA) supplemented with $10 \%$ fetal bovine serum (Atlanta Biologicals, 
Lawrenceville, GA), 10 mM HEPES (Mediatech), $4 \mathrm{mM}$ L-glutamine (Mediatech), $1 \mathrm{mM}$ sodium pyruvate (Mediatech), $100 \mathrm{IU}$ penicillin (Mediatech) and $100 \mu \mathrm{g} / \mathrm{ml}$ streptomycin (Mediatech). SK-OV-3 and OVCAR-3 ovarian cancer cells were from ATCC, and routinely maintained in RPMI 1640 (Mediatech) supplemented with $10 \%$ fetal bovine serum (Atlanta Biologicals), $10 \mathrm{mM}$ HEPES (Mediatech), $4 \mathrm{mM} \mathrm{L-glutamine} \mathrm{(Mediatech),}$ 0.45\% D-(+)-glucose (Sigma Chemical Co., St. Louis, MO), $1 \mathrm{mM}$ sodium pyruvate (Mediatech), $1 \mathrm{X}$ nonessential amino acids (Mediatech), 100 IU penicillin (Mediatech), $100 \mu \mathrm{g} / \mathrm{ml}$ streptomycin (Mediatech), and $0.01 \mathrm{mg} / \mathrm{ml}$ human insulin (Roche, Indianapolis, IN). The androgen-responsive human prostate carcinoma LNCaP and androgen-unresponsive PC-3 cells were from ATCC and maintained in RPMI 1640 (Mediatech) supplemented with $10 \%$ fetal bovine serum (Atlanta Biologicals), $10 \mathrm{mM}$ HEPES (Mediatech), 4 mM L-glutamine (Mediatech), 1 $\mathrm{mM}$ sodium pyruvate (Mediatech), 100 IU penicillin (Mediatech), and $100 \mu \mathrm{g} / \mathrm{ml}$ streptomycin (Mediatech). The human breast adenocarcinoma MCF-7 cells were obtained from ATCC and maintained in DMEM (Mediatech) supplemented with $10 \%$ fetal bovine serum (Atlanta Biologicals), $10 \mathrm{mM}$ HEPES (Mediatech), $4 \mathrm{mM}$ L-glutamine (Mediatech), $1 \mathrm{mM}$ sodium pyruvate (Mediatech), $100 \mathrm{IU}$ penicillin (Mediatech), $100 \mu \mathrm{g} / \mathrm{ml}$ streptomycin (Mediatech), $1 \mathrm{X}$ non-essential amino acids (Mediatech), and $0.01 \mathrm{mg} / \mathrm{ml}$ human insulin (Roche). All cell lines were cultured at $37^{\circ} \mathrm{C}$ in a humidified atmosphere in the presence of $5 \% \mathrm{CO}_{2}$. Treatment of the cells with $\mathrm{MF}$ (Sigma) used a 20,000 $\mu \mathrm{M}$ stock solution of the drug in DMSO (Mediatech). The maximal concentration of DMSO in medium was $0.2 \%(\mathrm{v} / \mathrm{v})$. We have shown previously that cancer cells responded similarly to micromolar concentrations of MF when cultured in media without phenol red and charcoal-extracted fetal bovine serum or media containing unextracted serum and having phenol red [13]. Consequently in this work all experiments were conducted using media with unextracted serum and in the presence of phenol red.

\section{Cell proliferation and doubling times}

To measure proliferation in the presence of MF, cells were seeded into 6-well plates at a density selected to ensure exponential growth of each cell line while preventing the cells from reaching $100 \%$ confluence over the course of the experiment. Following a period of 24 $\mathrm{h}$ allotted for cell adherence, the cells were cultured in the continuous presence of MF or DMSO for $72 \mathrm{~h}$. Triplicate cultures were trypsinized, pelleted by centrifugation at $500 \mathrm{~g}$ for $5 \mathrm{~min}$, and resuspended in the appropriate growth medium. An aliquot of each cell suspension was combined with ViaCount reagent (Guava Technologies, Hayward, CA) resulting in a $1: 10(\mathrm{v} / \mathrm{v})$ dilution and then studied using the Guava ViaCount application in the Guava EasyCyte Mini microcapillary cytometer (Guava Technologies) as we previously described [15]. The data were acquired and analyzed using the CytoSoft 4.1 software (Guava Technologies). When indicated, the concentrations of MF required to inhibit cell proliferation by $50 \%$ or $\mathrm{IC}_{50}$ were determined using software designed to study drug interaction that calculates the median effective dose, Dm, which is analogous to the $\mathrm{IC}_{50}$ (Calcusyn, Biosoft, Cambridge, UK). To obtain cell culture doubling times (DT), cells were plated at a density equal to that used in dose-response experiments and allowed to grow in culture for $96 \mathrm{~h}$. Cells were harvested in triplicate and counted by microcytometry (Guava technologies) every $12 \mathrm{~h}$. A nonlinear regression analysis designed to estimate the DT of exponentially growing cells was conducted for each growth curve using Prism 5.0 computer software (GraphPad, San Diego, CA) and an equation that fits a rate constant to a data set demonstrating exponential growth. The rate constant $(\mathrm{K})$ was then used to calculate a value for DT as follows: DT $=\ln (2) / \mathrm{K}$.

\section{Cell cycle analysis}

Cells exposed to either vehicle or MF for $72 \mathrm{~h}$ were trypsinized, pelleted by centrifugation at $500 \mathrm{~g}$ for $5 \mathrm{~min}$, resuspended in the appropriate growth medium, and fixed with $4 \%$ paraformaldehyde. An aliquot ranging from 40,000300,000 cells (varying by treatment and cell line) was then washed with PBS and pelleted by centrifugation at $500 \mathrm{~g}$ for $5 \mathrm{~min}$. Cells were resuspended in $200 \mu \mathrm{l}$ of cell cycle buffer [3.8 mM sodium citrate (Sigma), $7 \mathrm{U} / \mathrm{ml}$ RNase A (Sigma), 0.1\% (v/v) Triton X-100 (Sigma), and $0.05 \mathrm{mg} / \mathrm{ml}$ propidium iodide (Sigma)] at a concentration of 200-1,500 cells $/ \mu \mathrm{l}$, and analyzed for the capacity of their DNA to bind propidium iodide utilizing the Guava EasyCyte Mini microcapillary cytometer and the cell cycle application of the CytoSoft 4.1 software.

\section{SDS-PAGE and Western blotting}

Cells were scraped, pelleted, and washed twice with PBS, then snap frozen followed by storage at $-80^{\circ} \mathrm{C}$. Cells were lysed by the addition of NP-40 lysis buffer containing $50 \mathrm{mM}$ Tris- $\mathrm{HCl}$ ( $\mathrm{pH} 7.5$ ), $150 \mathrm{mM} \mathrm{NaCl}, 0.5 \%$ NP40 (Sigma), $50 \mathrm{mM}$ sodium fluoride (Sigma), $1 \mathrm{mM}$ PMSF (Sigma), $1 \mathrm{mM}$ dithiothreitol (Invitrogen, Carlsbad, CA), $2 \mu \mathrm{g} / \mathrm{ml}$ pepstatin (Sigma), $2 \mu \mathrm{g} / \mathrm{ml}$ leupeptin (Sigma), $2 \mu \mathrm{g} / \mathrm{ml}$ aprotinin (Sigma), and $1 \mathrm{mM}$ orthovanadate (Sigma). Lysates were centrifuged at 16,000 $g$ for $20 \mathrm{~min}$ at $4^{\circ} \mathrm{C}$, and the supernatant was considered the whole cell extract, which was assayed for protein content using the bicinchoninic acid method (BCA; Pierce, Rockford, IL). Whole cell extracts were appropriately diluted in $3 \mathrm{X}$ concentrated electrophoresis sample 
buffer and boiled for $10 \mathrm{~min}$. Equivalent amounts of protein $(100$ or $50 \mu \mathrm{g})$ were loaded in fixed $7.5 \%$ or $12 \%$ polyacrylamide gels, subjected to SDS-PAGE and transferred to PVDF membranes. The blots were blocked in $5 \%(\mathrm{v} / \mathrm{v})$ nonfat milk in TBS containing $0.1 \%(\mathrm{v} / \mathrm{v})$ Tween $20(\mathrm{~T})$, and then probed overnight with primary antibodies against PR (clone hPRa7; $4 \mu \mathrm{g} / \mathrm{mL}$; Thermo Fisher Scientific, Fremont, CA; or \#1483-1; 1:1,000; Epitomics, Burlingame, CA), GR (\#sc-1003; 1:1,000; Santa Cruz Biotechnology, Santa Cruz, CA), AR (\#1852-1; 1:10,000; Epitomics), ER- $\alpha$ (\#4200-1; 1:1,000; Epitomics), p21 ${ }^{\text {cip1 }}$ (clone 6B6; $2 \mu \mathrm{g} / \mathrm{mL}$; BD Biosciences, San Diego, CA), p27 ${ }^{\text {kip } 1}$ (clone 57; 1:2,000; BD Transduction Laboratories, San Diego, CA), cyclin E (clone HE12; 0.5 $\mu \mathrm{g} / \mathrm{ml}$; BD Pharmigen, San Diego, CA), and Cdk2 (M2; \#sc-163; 1:1,000; Santa Cruz Biotechnology). The membranes were washed $3 \times 5 \mathrm{~min}$ in TBS-T and incubated with a 1: 10,000 dilution of peroxidase-conjugate secondary antibody (\#111-035-003 or \#115-035-003; Jackson ImmunoResearch Laboratories, West Grove, PA) for $30 \mathrm{~min}$ at room temperature. The blots were again washed, developed by chemiluminescence, and exposed to radiographic film. Blots were also probed with an antibody directed against $\beta$-Actin (clone AC-15; 1:20,000; Sigma) to control for protein loading. When indicated, densitometry was used to compare protein expression using Image 1.43 software (National Institutes of Health, Bethesda, MD).

\section{Cdk2 in vitro kinase assay}

An aliquot (100 $\mu \mathrm{g}$ of protein) from each NP-40 cell lysate was incubated overnight at $4{ }^{\circ} \mathrm{C}$ with constant rotation in 1 $\mathrm{ml}$ of NP-40 lysis buffer containing $1 \mu \mathrm{g}$ polyclonal rabbit antibody to Cdk2 (M2; \#sc-163; Santa Cruz Biotechnology). Immunocomplexes associated with $\mathrm{Cdk} 2$ were collected after incubating for $2 \mathrm{~h}$ with protein A/G PLUSAgarose beads (Santa Cruz Biotechnology). The immune complexes were washed three times with NP-40 lysis buffer and twice with kinase buffer [50 mM HEPES (pH 7.2), $10 \mathrm{mM} \mathrm{MgCl}, 1 \mathrm{mM}$ DTT, $10 \mathrm{mM} \beta$-glycerophosphate, and $1 \mathrm{mM}$ sodium fluoride]. Subsequently, the beads were resuspended in $30 \mu \mathrm{l}$ of kinase buffer containing $2 \mu \mathrm{g}$ histone H1 (Upstate Cell Signaling Solutions, Lake Placid, NY), $5 \mu \mathrm{M}$ ATP (Upstate), and $5 \mu \mathrm{Ci}\left[\gamma^{32} \mathrm{P}\right]$ ATP (MP Biomedicals; Irvine, $\mathrm{CA}$ ). The reaction mixtures were incubated at $30^{\circ} \mathrm{C}$ for $30 \mathrm{~min}$ and then terminated with $30 \mu \mathrm{l}$ of $2 \mathrm{X}$ electrophoresis sample buffer, boiled, and separated on $12 \%$ SDS-PAGE. Gels were stained with Coomassie blue (Sigma) to visualize the histone H1 bands, dried, and autoradiographed.

\section{Statistical analysis}

All data are reported as mean \pm SEM, and statistical significance was defined as $P<0.05$. To compare cell cycle kinetics and hypodiploid DNA distribution, one-way analysis of variance (ANOVA) followed by the Tukey's multiple comparison test was used as appropriate.

\section{Results}

MF inhibits the growth of tumor cells of the nervous system, breast, prostate, ovary, and bone

A panel of 10 cancer cell lines was selected to assess the capacity of MF to inhibit the growth of cancer cells originating from the nervous system, breast, prostate, ovary and bone. A series of dose-response experiments was conducted to study the effect of $72 \mathrm{~h}$ exposure to MF on cell growth. In accordance with our hypothesis, MF inhibited the growth of the entire panel of cancer cells included in the study in a dose-related manner (Figure 1). We compared the growth inhibitory potency of MF among cell lines quantitatively by comparing the mean $\mathrm{IC}_{50}$ values representing at least 3 independent experiments for each cell line (Table 1). The DT for each cell line was indicated in the table and its calculation depicted in Additional File 1, Figure S1. Using this method, IOMM-Lee, LNCaP, and SK-OV-3 cells displayed lower $\mathrm{IC}_{50 \text { s }}$ to MF-induced growth inhibition while MCF-7, PC-3, OVCAR-3, U87MG, U-2OS, and SAOS-2 cells responded to MF at higher $\mathrm{IC}_{50 \mathrm{~s}}$. MDA-MB-231 cells were the least sensitive to growth inhibition by MF as indicated by the highest $\mathrm{IC}_{50}$. Overall all cell lines responded to the growth inhibitory effect of MF with $\mathrm{IC}_{50 \text { s }}$ ranging from $\sim 9$ to $30 \mu \mathrm{M}$.

\section{MF induces G1 accumulation in select cancer cell lines}

To analyze the effect of MF treatment on cell cycle traverse, each cell line was cultured in the presence of vehicle or MF for $72 \mathrm{~h}$, harvested, and stained with propidium iodide; the distribution of cells with DNA content characteristic of G1, S, or G2/M phases of the cell cycle, as well as the proportion of cell particles with hypodiploid DNA content-encompassing particles from dead cells-was analyzed by microcytometry. Figure 2 represents the cell cycle distributions of all cell lines following exposure to MF. Consistent with our previous findings in ovarian cancer cells, we observed an accumulation of cells with DNA content representative of G1 phase in the U87MG, MCF-7, PC-3, and SK-OV-3 lines (Figure 2A). A significant accumulation of cells in G1 phase was observed at a concentration of $10 \mu \mathrm{M}$ of MF in PC-3 cells and of $20 \mu \mathrm{M}$ of MF in MCF-7 cells. While statistical significance was not achieved with U87MG and SK-OV-3 cells, the trend of G1 accumulation was apparent. G1 accumulation occurred in a dosedependent manner in these 4 cell lines, with a slight decrease at a concentration of $40 \mu \mathrm{M}$ MF corresponding to an increase in hypodiploid DNA content, indicating cellular lethality at this high concentration of the steroid (see below; Figure 3). The accumulation of cells with G1 
A

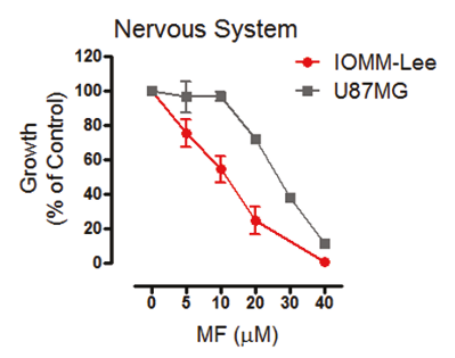

B

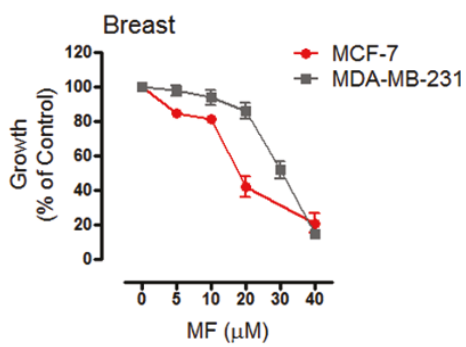

C

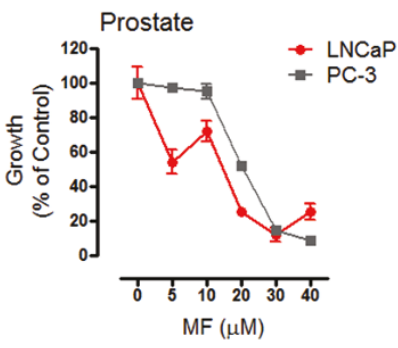

D

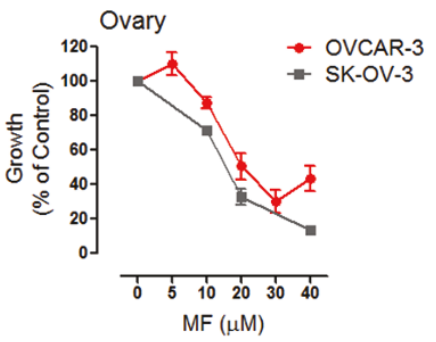

$E$

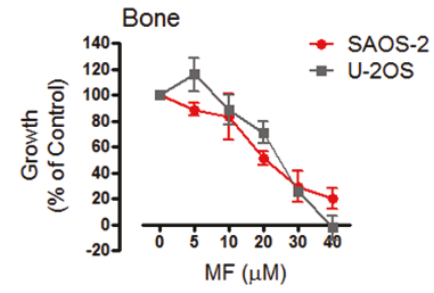

Figure $1 \mathrm{MF}$ inhibits the growth of tumor cell lines of the nervous system (A), breast (B), prostate (C), ovary (D), and bone (E). Cells were seeded at a density appropriate for each cell line, allowed to adhere for $24 \mathrm{~h}$, and then exposed to the indicated concentrations of MF for $72 \mathrm{~h}$. At the end of the experiment, cells were harvested by trypsinization and counted by microcytometry. Growth curves are expressed as the percent-growth of MF-treated cells with respect to vehicle-treated cell growth. The growth of vehicle-treated cells was calculated as the difference between the total number of cells at $0 \mathrm{~h}$ and $72 \mathrm{~h}$ of treatment, and was designated as $100 \%$ growth. Data points represent the mean \pm s.e. $\mathrm{m}$. of at least 3 independent experiments completed in triplicate.
Table 1 Concentration of MF needed to achieve $50 \%$ growth inhibition $\left(\mathrm{IC}_{50}\right)$ of the cell lines studied and their doubling times (DT)

\begin{tabular}{lllc}
\hline Origin & Cell Line & IC $_{\mathbf{5 0}}(\boldsymbol{\mu M})$ & DT $(\mathbf{h})$ \\
\hline N. System & IOMM-Lee & $9.4 \pm 1.2$ & 13.9 \\
N. System & U87MG & $23.2 \pm 0.0$ & 36.9 \\
Breast & MCF-7 & $17.7 \pm 2.0$ & 37.7 \\
Breast & MDA-MB-231 & $29.2 \pm 1.3$ & 33.3 \\
Prostate & LNCaP & $14.1 \pm 0.5$ & 50.7 \\
Prostate & PC-3 & $18.5 \pm 2.0$ & 30.7 \\
Ovary & OVCAR-3 & $19.0 \pm 1.3$ & 55.7 \\
Ovary & SK-OV-3 & $12.6 \pm 0.1^{*}$ & 36.9 \\
Bone & U-2OS & $21.9 \pm 2.3$ & 29.2 \\
Bone & SAOS-2 & $18.7 \pm 3.2$ & 49.2 \\
\hline
\end{tabular}

$\mathrm{IC}_{50}$ data are expressed as mean \pm s.e.m of three experiments each one performed in triplicate. DT data are the result of one experiment performed in triplicate (see Additional file 1: Figure S1). *Date obtained from our previously published work [14].

DNA content was accompanied by a dose-dependent decrease in the proportion of cells with DNA content characteristic of $\mathrm{S}$ and $\mathrm{G} 2 / \mathrm{M}$ phases (Figure $2 \mathrm{~B}$ and $2 \mathrm{C}$ ). Alternately, cell cycle distributions of IOMM-Lee, MDA-MB231, LNCaP, OVCAR-3, U-2OS and SAOS-2 lines did not show an apparent accumulation of cells with G1 DNA content upon $72 \mathrm{~h}$ exposure to MF (Figure 2D). Instead, the proportion of G1 DNA content remained fairly constant at lower doses of MF and then decreased as these cell lines became susceptible to the lethality of higher drug concentrations. In this subset of cell lines, we also observed a decrease in the proportion of cells with DNA content characteristic of $\mathrm{S}$ and $\mathrm{G} 2 / \mathrm{M}$ phases that was most notable at higher concentrations of MF (Figure 2E and 2F).

\section{Cancer cell lines associated with MF-induced G1 arrest exhibit lower lethality at a high concentration of MF} Cell particles with hypodiploid DNA content were considered to represent the proportion of dying cells. We observed that the subset of cell lines that did display an accumulation in G1 phase upon exposure to MF appeared less susceptible to lethality induced by high concentration of MF than those that did not (Figure 3A and $3 \mathrm{~B}$ ). The mean difference in the proportion of cells with hypodiploid DNA content between $0 \mathrm{~h}$ and $72 \mathrm{~h}$ of treatment was calculated for each cell line, and then the mean lethality induced by the highest concentration of MF $(40 \mu \mathrm{M})$ was calculated for both subsets of cell lines. Cells accumulating in G1 phase displayed a modest induction of lethality by $40 \mu \mathrm{M}$ MF ranging from $5.3 \pm$ $2.7 \%$ (PC-3) to $12.9 \pm 5.1 \%$ (U87MG), with a mean of 8.7 $\pm 1.8 \%$ (Figure $3 \mathrm{~A}$ ). Cell lines without G1 accumulation were more sensitive to MF-induced lethality, ranging from $17.0 \pm 2.1 \%$ (SAOS-2) to $61.3 \pm 7.3 \%$ (LNCaP) with a mean lethality of $39.3 \pm 6.9 \%$ (Figure $3 \mathrm{~B}$ ). In summary, when we compared the difference between the mean 


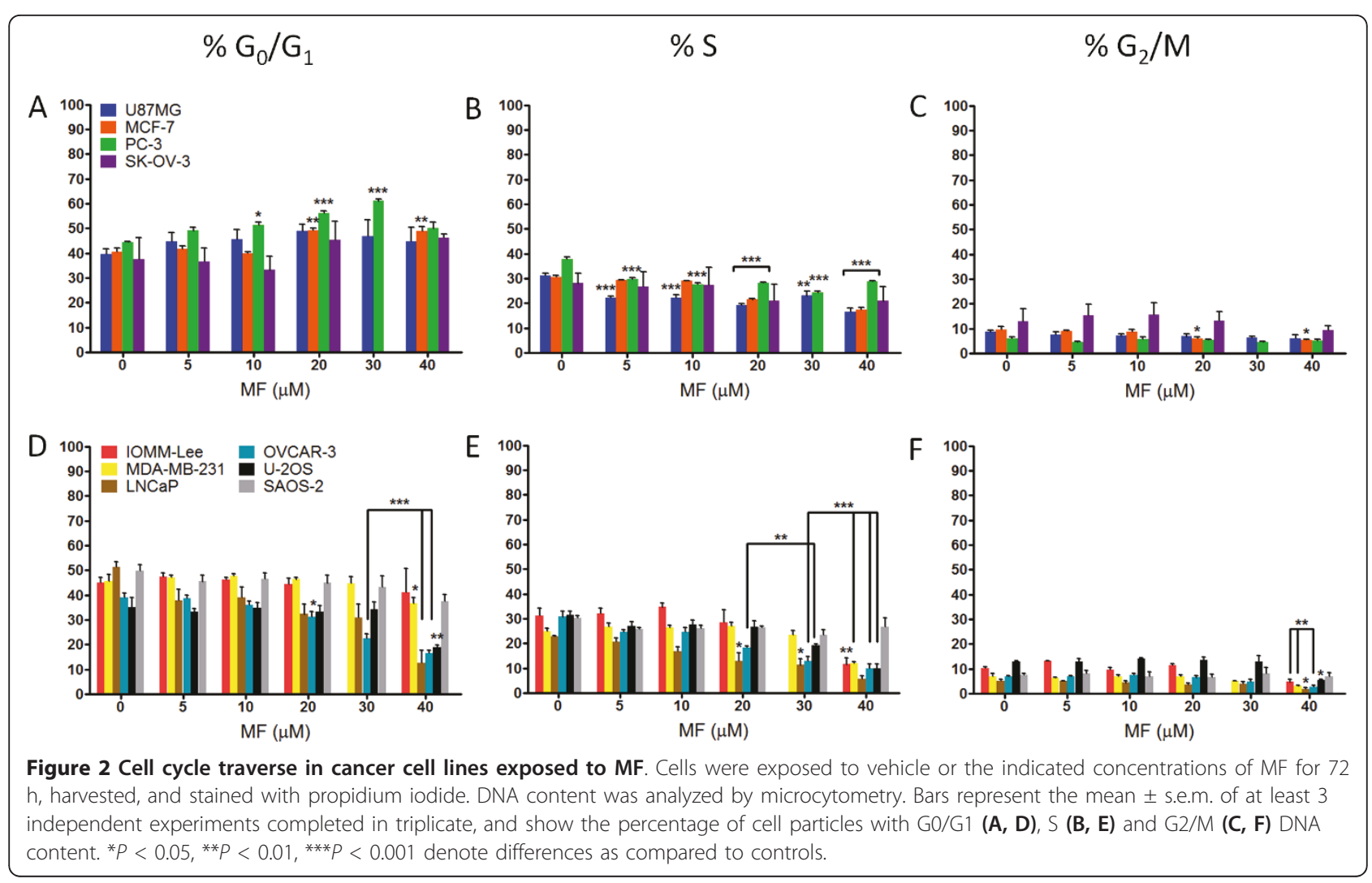

proportion of cells with hypodiploid DNA content at $0 \mathrm{~h}$ of treatment and after $72 \mathrm{~h}$ of exposure to $40 \mu \mathrm{M}$ of $\mathrm{MF}$ in all cancer cell lines, we found that a lack of observable G1 accumulation in response to MF was associated with significantly greater lethality.
The cytostatic effect of MF in the cancer cells studied is associated with a decline in the activity of Cdk2

$\mathrm{Cdk} 2$, in association with cyclin E, is mostly responsible for allowing cells to engage the process of DNA synthesis during the $\mathrm{S}$ phase of the cell cycle, whereas $\mathrm{p} 21^{\text {cip1 }}$

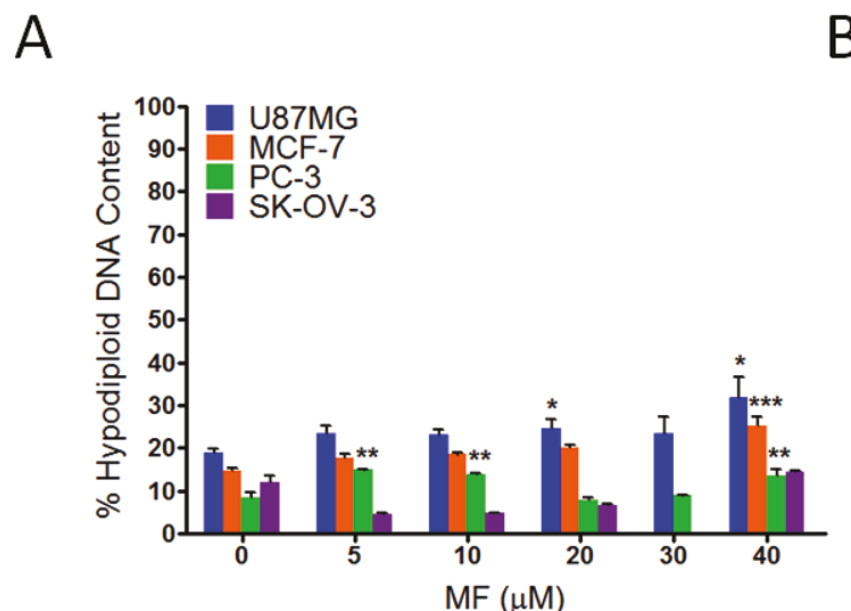

B

Figure 3 Hypodiploid DNA content in MF-treated cancer cells. Cells were exposed to vehicle or MF for $72 \mathrm{~h}$, harvested, and stained with propidium iodide. DNA content was analyzed by microcytometry. Bars represent the mean \pm s.e.m. of at least 3 independent experiments completed in triplicate, and show the percentage of cell particles with hypodiploid DNA content indicative of cell death. (A) A modest increase in the proportion of cells with hypodiploid DNA content was observed in cell lines that responded to MF by accumulating in G1 phase (see Figure 2). (B) A large, dose-dependent increase in the proportion of cell particles with hypodiploid DNA content was observed in cell lines that did not show an accumulation in G1 phase in response to increasing concentrations of MF (see Figure 2 ). ${ }^{*} P<0.05,{ }^{* *} P<0.01,{ }^{* * *} P<0.001$ denote difference as compared to controls. 
and $\mathrm{p} 27^{\mathrm{kip} 1}$ are usually involved in inhibiting cyclin E/Cdk2 activity [24]. Previous work in our laboratory has pointed to a reduction in $\mathrm{Cdk} 2$ activity as a potential mechanism of MF-induced growth arrest [13]. We therefore questioned whether a similar reduction in the activity of this enzyme would be translated to this panel of cell lines expanding various cancers. In all cells lines exposed to either $\mathrm{MF} \mathrm{IC}_{50}$ and/or $\mathrm{IC}_{75}$, the activity of Cdk2 was reduced when treated with MF (Figure 4A and $4 \mathrm{~B})$. The decline in Cdk2 activity induced by MF was accompanied by increased $\mathrm{p} 21^{\mathrm{cip} 1}$ abundance in U87MG, MCF-7, OVCAR-3, LNCaP, PC-3 and SK-OV3 cells; increased p $27^{\mathrm{kip} 1}$ levels in U87MG, MCF-7, LNCaP, and OVCAR-3 cells; decreased levels of Cdk2 in SAOS-2, MDA-MB-231, LNCaP, and PC-3 cells; and reduced cyclin $\mathrm{E}$ in SAOS-2 and SK-OV-3 cells.
The efficacy of MF as a cytostatic agent in cancer cells is not related to the expression of progesterone receptor, androgen receptor, or estrogen receptor

Since MF was effective in growth inhibiting the 10 human cancer cell lines included in this study, we subsequently evaluated in all cells the expression levels of classical, nuclear PR isoforms A (PR-A) and B (PR-B), GR isoforms alpha $(\mathrm{GR}-\alpha)$ and beta $(\mathrm{GR}-\beta), \mathrm{AR}$, and ER isoform alpha $(E R-\alpha)$ to determine whether there is a correlation between the expression of one or more receptor types and the sensitivity to MF-induced growth inhibition when MF is used at cytostatic, non-lethal doses. We were particularly interested in the role of classical PR isoforms which are anticipated to be the primary targets and mediators of the antiprogestin activity of MF [25]. We also decided to study the expression

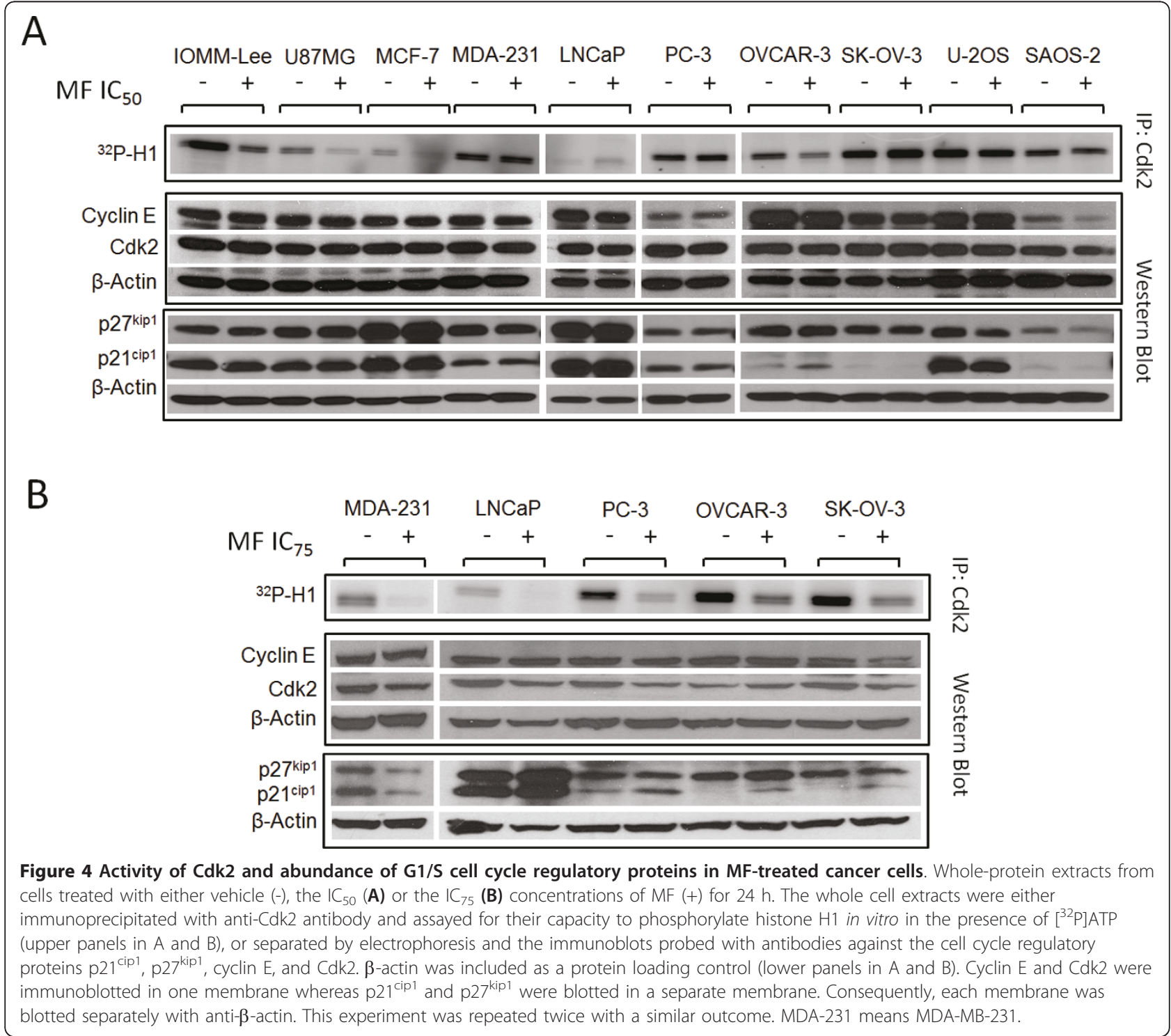


of receptors in the absence or presence of MF considering that previous reports suggest that GR and PR are modulated by the drug $[17,26]$. Cells were grown to 50 $70 \%$ confluence and were exposed to either vehicle or an $\mathrm{IC}_{50}$ concentration of MF for $24 \mathrm{~h}$ prior to harvesting. Cells were lysed, and whole protein extracts were immunoblotted for the presence of PR-A, PR-B, GR- $\alpha$, GR- $\beta$, AR, and ER- $\alpha$. Figure 5 shows the steroid hormone receptor expression levels in all cell lines treated with either vehicle or MF. In vehicle-treated cells, utilizing two different anti-human PR primary antibodies that recognize both $\mathrm{PR}$ isoforms with varied efficacy, we detected PR-A and PR-B only in MCF-7 breast cancer cells. MCF-7 and SK-OV-3 cells expressed ER- $\alpha$, whereas only prostate LNCaP cells expressed AR. All cell lines expressed GR- $\beta$, while GR- $\alpha$ appeared to be nearly absent or at very low concentrations in MCF-7, LNCaP, OVCAR-3, U-2OS, and SAOS-2 cells, but more abundant in IOMM-Lee, U87MG, MDA-MD-231, PC-3, and SK-OV-3 cells. Additionally, in response to a cytostatic concentration of MF, we found a decrease in the abundance of nearly all steroid hormone receptors expressed. Both PR isoforms decreased in MCF-7 cells following $24 \mathrm{~h}$ exposure to $\mathrm{MF}$ regardless of the PR antibody utilized. Similarly, the expression of AR in LNCaP prostate cancer cells exposed to MF decreased, a slight decrease in the abundance of ER- $\alpha$ was observed in MCF-7 and SK-OV-3 cells, whereas GR- $\alpha$ slightly declined in some but not all cell lines treated with MF. Conversely GR- $\beta$ did not apparently change among vehicle-treated vs. MF-treated cells in any investigated cell line.

\section{Discussion}

We have shown that MF is able to inhibit the growth of cancer cells derived from the nervous system, breast, prostate, ovary, and bone, with nearly all of them not expressing the classical, nuclear PR. Mainstream literature on the anti-cancer effect of MF assumes that it acts as a PR antagonist, which implies that PR in the target tissue is a pre-requisite for MF's anti-growth activity. Our present work challenges such a dogma, opening the field of study to alternate, non-classical mechanisms whereby MF operates as a cell growth inhibitor without the necessity of nuclear PR being present or operational. If these results were translated into the clinic, the presence or absence of classical, nuclear PR would not be relevant and would not impact the usage of this drug for cancer therapy.

Dose-response experiments, in which a panel of 10 cancer cell lines were exposed to increasing concentrations of MF, indicated that micromolar doses of MF were effective to inhibit the growth of malignant meningioma IOMM-Lee cells, glioblastoma U87MG cells, breast cancer MCF-7 and MDA-MB-231 cells, prostate cancer LNCaP and PC-3 cells, ovarian cancer OVCAR-3

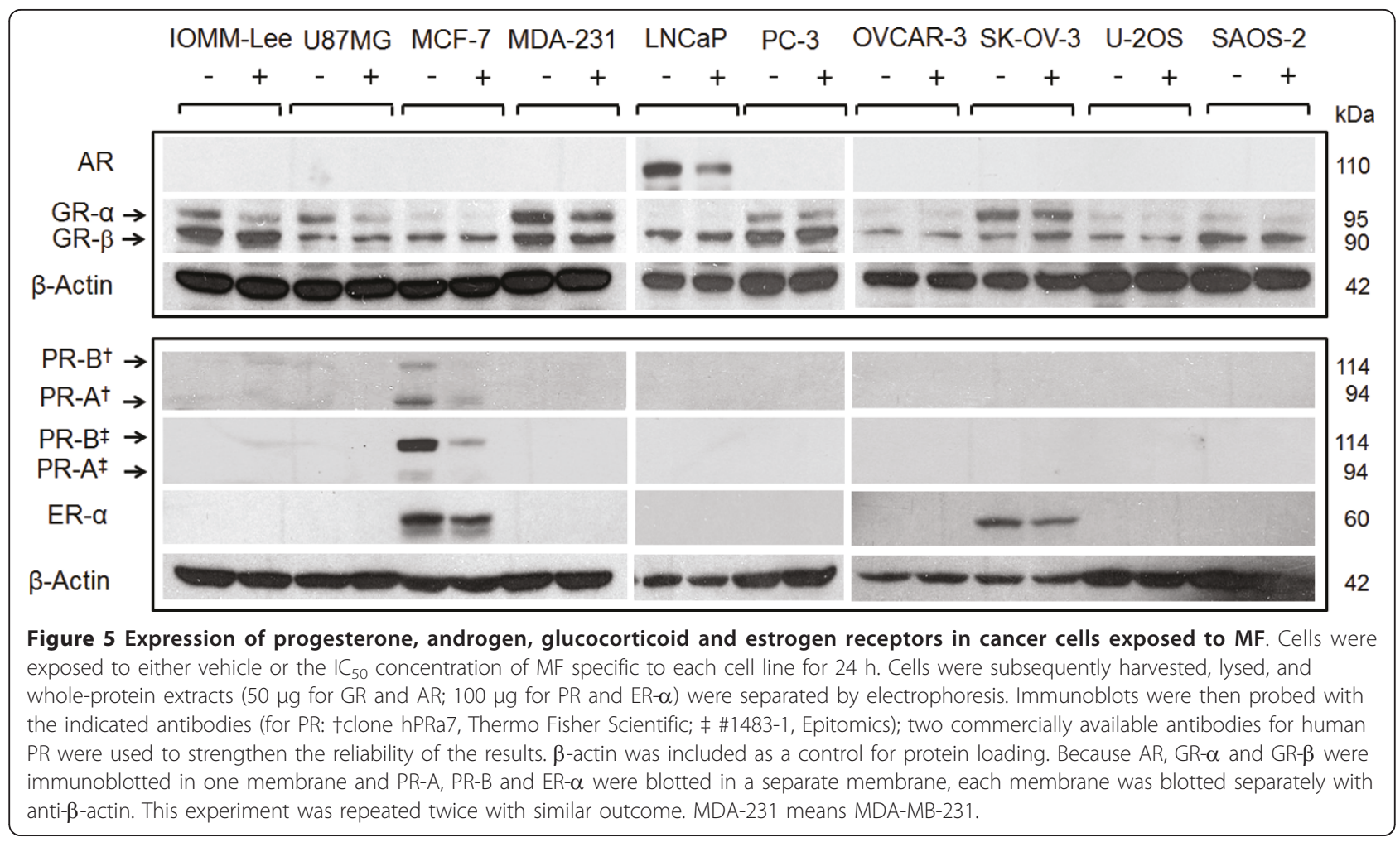


and SK-OV-3 cells, and osteosarcoma U-2OS and SAOS-2 cells; in all cell lines studied MF was cytostatic at lower micromolar doses but lethal at higher micromolar concentrations. We selected the U87MG cell line based on the aggressive nature of malignant glioma, their reported lack of PR expression [27], and the reported efficacy of MF in delaying their growth both in vitro and in vivo [27]. The malignant meningioma IOMM-Lee cell line [28] was the second line selected from the nervous system because over $70 \%$ of meningiomas express PR [29], and clinical trials conducting longterm MF treatment of patients with unresectable meningioma have been promising [30,31]; yet the expression of PR in IOMM-Lee was, to our knowledge, unknown. Our study shows that MF growth arrests IOMM-Lee malignant meningioma cells which lacked PR expression, suggesting that the presence of PR may not be required for $\mathrm{MF}$ to operate as a growth inhibitor in this cancer type. MCF-7 breast cancer cells are known to be responsive to estrogen and to express $P R$ and ER [32-34], while triple negative MDA-MB-231 (i.e., cells lacking PR, ER- $\alpha$, and HER2) are highly aggressive [7]. Previous studies demonstrated the efficacy of MF as single agent or in combination with 4-hydroxy-tamoxifen in growth-inhibiting both cell lines [7,35-38]. Our data confirm those results and find that triple negative MDA-MB-231 cells are slightly less responsive to MF than estrogen-responsive MCF-7 cells (Table 1). Similarly in LNCaP and PC-3 prostate cancer cells, classified respectively as androgen-sensitive and androgen-insensitive, MF was efficacious in growth-inhibiting both cell lines, confirming previous data using androgen-refractory LNCaP cell variants in vitro $[8,12]$ and in vivo $[12,39]$. PR does not appear to be related to primary prostate tumors, but increased $P R$ expression was observed in prostate metastasis [40]. LNCaP cells were reported to express PR-A and PR-B mRNA, yet PC-3 were shown not to express PR [41]. We were unable to detect PR proteins in either of these cell lines but found that LNCaP cells were slightly more responsive than PC-3 cells to MF (Table 1), which may be related to the capacity of MF to partially bind AR that are present in LNCaP but not in PC-3 [42]. In ovarian cancer, OVCAR-3 cells have been reported to express PR only in vivo upon estradiol stimulation [19], while as indicated earlier in the introduction, PR expression in SKOV-3 ovarian cancer cells is controversial. Both cell lines were shown to be sensitive to growth inhibition by MF in vitro $[13,16]$ and in vivo [13], what we further confirm in this study. Once again, the presence of PR does not appear to be a pre-requisite for the cells to respond to MF. Finally, we studied two osteosarcoma cell lines of different genetic backgrounds, which were reported to express no PR and very low levels of GR- $\alpha$
[43]. We confirmed the lack of PR and the low levels of GR- $\alpha$ protein but instead found GR- $\beta$ with values that were slightly higher in SAOS-2 than in U-2OS cells. While all cell lines studied were growth inhibited by MF, PR expression was observed only in MCF-7 breast cancer cells known to be estradiol-responsive and to express both PR-A and PR-B isoforms [32-34]. AR was observed only in the androgen-dependent LNCaP prostate cancer cells, which is consistent with the reported expression of AR when these cells were first characterized [44]. In accordance with the reported expression of ER in MCF-7 cells [45], we detected ER- $\alpha$ in this cell line. While only a few of the cell lines included in this study expressed PR, AR, and/or ER- $\alpha$, all cell lines were sensitive to the cytostatic and lethal effects of MF, suggesting that the expression of PR, AR, and ER- $\alpha$ is not required for $\mathrm{MF}$ to act as a growth inhibitor agent. Presence of MF reduced the expression of PR and ER- $\alpha$ in MCF-7 cells, AR in LNCaP cells, and ER- $\alpha$ in SK-OV-3 cells further discouraging the role of these receptors as mediators of the growth inhibitory effect of MF given that the cytostatic property of MF can be maintained long after those receptors are down-regulated.

Our previous studies in ovarian cancer cells indicated that MF-induced growth inhibition occurs through G1 cell cycle arrest and a profound inhibition of the G1/S kinase, Cdk2 [13]. In the present study, analysis of cell cycle kinetics following $72 \mathrm{~h}$ exposure of each cell line to MF showed the accumulation of cells with G1 phase DNA content in U87MG, MCF-7, PC-3, and SK-OV-3 cells, yet 6 cell lines in this study did not respond to MF with G1 arrest. Instead, we observed either a maintenance of the proportion of cells in each phase of the cell cycle up to a lethal concentration of MF (IOMMLee, MDA-MB-231, U-2OS, and SAOS-2 cells), or a steady decline in the proportion of cells in each phase of the cell cycle beginning at low concentrations of MF with a corresponding increase in cells with hypodiploid DNA content (LNCaP and OVCAR-3 cells). Despite these differences, the decline in the activity of Cdk2 within $24 \mathrm{~h}$ of exposure to MF was a commonality among the 10 cell lines studied (Figure 4), as we have shown in ovarian cancer cells for MF [13] and more recently for two other antiprogestins, ORG-31710 and CDB-2914 [46].

In this work evidence has ruled out that classical, nuclear PR must be expressed in a cancer cell to respond to the cytostatic activity of the so-classified antiprogestin MF. Further studies will need to be conducted to define the molecular targets and mediators of MF's action. Though all cell lines studied express variable levels of GR- $\alpha$ and GR- $\beta$, we could not find any correlation between the relative growth inhibitory response of the cells to MF and the relative abundance 
of GR- $\alpha(\mathrm{r}=-0.1831 ; P=0.612)$, GR $-\beta(\mathrm{r}=0.0834 ; P$ $=0.818)$ or the ratio GR $-\alpha / \mathrm{GR}-\beta(\mathrm{r}=-0.2366 ; P=$ 0.510 ) as determined by densitometry analysis of the Western blots presented in Figure 5 and corrected by $\beta$ actin loading. MF was designed in the mid-1980s with the purpose of treating Cushing's syndrome by working as a potent anti-glucorticoid agent [4,47]. Indeed MF binds GR- $\alpha$ with mostly antagonistic activity; yet it may have agonistic potency depending on the concentration of GR in the cell [48]. Although GR- $\beta$ has been considered a dominant-negative regulator of GR- $\alpha$ [49-51], it was also reported that MF was the only compound of 57 potential natural and synthetic ligands to bind to the GR- $\beta$ receptor isoform, and that interaction of GR- $\beta$ with MF led to its nuclear translocation [52]. Additionally, this latter study found that despite its classification as a dominant-negative isoform lacking transcriptional activity, GR- $\beta$ was capable of regulating gene expression in the absence of GR- $\alpha$, and this activity was modulated by interaction with MF. A more recent study also reported intrinsic transcriptional activity of GR- $\beta$ independent of GR- $\alpha$, but neither found an association between MF binding and nuclear translocation of GR- $\beta$ nor could detect modulation of GR- $\beta$ transcriptional activity by MF [53], adding controversy to the actual activity of MF on GR- $\beta$. This evidence and our results strongly suggest that further studies need to be conducted to determine any role of either GR isoform on the anti-growth activity of MF.

A possibility exists in that the newly discovered progesterone receptor membrane component 1 (PGRMC1) $[54,55]$ or the family of membrane PRs $(\mathrm{mPR} \alpha, \beta, \gamma, \delta$, ع) [55-57] mediate the anti-tumor effects of MF. For instance, PGRMC1 expression increases while cognate, nuclear PR decreases in advanced stages of ovarian cancer, and overexpression of PGRMC1 interferes with the lethality of cisplatin, suggesting a survival role for PGRMC1 in ovarian cancer development [58]. In a panel of ovarian cancer cell lines expressing abundant $\mathrm{mPR} \alpha, \mathrm{mPR} \beta$, and $\mathrm{mPR} \gamma$, but not classical nuclear PR-A and $-\mathrm{B}$, exposure to progesterone mediated the expression of pro-apoptotic proteins via activation of JNK and p38 MAPKs [22]. Given that at micromolar concentrations MF functions as an agonist on both $\mathrm{mPR} \alpha$ and $\operatorname{mPR} \gamma$ when expressed in yeast [59], it is conceivable that MF may mediate antiproliferation of cancer cells acting as an agonist of mPRs.

At micromolar doses, MF may have an alternate mechanism of action. For instance MF has a potent antioxidant effect when used at micromolar concentrations and attributed to the presence of the dimethylamino phenyl side chain of the molecule [60]. In endometrial cells and macrophages, the growth inhibitory effect of MF was partially attributed to the antioxidant property of the compound $[61,62]$. A putative antioxidant property of MF in cancer cells would be relevant in the context of $\mathrm{p} 21^{\mathrm{cip} 1}$ induced G1 arrest as $\mathrm{p} 21^{\text {cip } 1}$ has been shown to be induced by some antioxidants in a p53-independent manner [63,64]. Another potential mechanism involved in MF's anti-growth activity is the induction of stress of the endoplasmic reticulum. For instance a recent study showed that MF induced an atypical unfolded protein response (UPR) in non-small lung cell carcinoma cells [65].

\section{Conclusions}

This study has shown that the canonical, nuclear PR is not required for MF to successfully inhibit the growth of a panel of 10 cancer cell lines of different genetic backgrounds, hormone-responsiveness, and tissues of origin. Our study is limited only to eliminate the dogma that classical PR should be present to consider the use of MF in cancer therapy. However, the present results warrant mechanistic studies to uncover the ultimate mediators of MF's anti-proliferative activity in cancer cells. The role of mPRs, PGRMC1 and GR- $\beta$ as mediators of MF anti-growth activity needs investigation. Furthermore the role of the endoplasmic reticulum responding to MF triggering the UPR, what could lead to either survival with cytostasis or death depending upon the concentration of MF, is a provoking hypothesis that deserves to be investigated.

\section{Additional material}

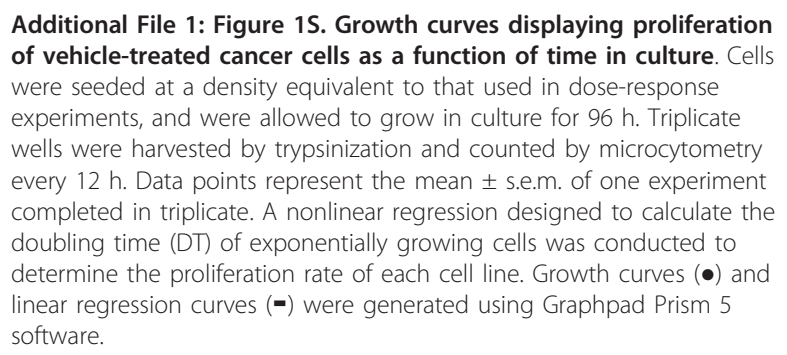

\section{Acknowledgements}

This work was supported by a subproject from the National Institutes of Health, Center of Biomedical Research Excellence (COBRE) of the National Center for Research Resources grant P20 RR-015567, and by award number K22CA121991 and ARRA supplement K22CA121991-S1 from the National Cancer Institute. We thank Mr. Nahuel Telleria for editing the manuscript.

\section{Authors' contributions}

CRT carried out most experiments and drafted the manuscript. AAG performed the Cdk2 in vitro kinase assays and assisted CRT in some of the experiments. BNB performed the cell cycle analysis of the osteosarcoma cell lines and assisted CRT with the art work. CTO performed the experiments to calculate the doubling times of the cell lines studied. CMT conceived the study and contributed to the writing of the final version of the manuscript. All authors analyzed the results, read and approved the final manuscript. 


\section{Competing interests}

The authors declare that there is no conflict of interest that could influence the impartiality of the research reported.

Received: 15 January 2011 Accepted: 27 May 2011

Published: 27 May 2011

\section{References}

1. Benagiano G, Bastianelli C, Farris M: Selective progesterone receptor modulators 1: use during pregnancy. Expert Opin Pharmacother 2008, 9(14):2459-2472

2. Benagiano G, Bastianelli C, Farris M: Selective progesterone receptor modulators 2: use in reproductive medicine. Expert Opin Pharmacother 2008, 9(14):2473-2485.

3. Moller C, Hoffmann J, Kirkland TA, Schwede W: Investigational developments for the treatment of progesterone-dependent diseases. Expert Opin Investig Drugs 2008, 17(4):469-479.

4. Benagiano G, Bastianelli C, Farris M: Selective progesterone receptor modulators 3: use in oncology, endocrinology and psychiatry. Expert Opin Pharmacother 2008, 9(14):2487-2496.

5. Horwitz KB: The antiprogestin RU38 486: receptor-mediated progestin versus antiprogestin actions screened in estrogen-insensitive T47Dco human breast cancer cells. Endocrinology 1985, 116(6):2236-2245.

6. Lin VC, Aw SE, Ng EH, Tan MG: Demonstration of mixed properties of RU486 in progesterone receptor (PR)-transfected MDA-MB-231 cells: a model for studying the functions of progesterone analogues. $\mathrm{Br} J$ Cancer 2001, 85(12):1978-1986.

7. Liang Y, Hou M, Kallab AM, Barrett JT, El Etreby F, Schoenlein PV: Induction of antiproliferation and apoptosis in estrogen receptor negative MDA231 human breast cancer cells by mifepristone and 4-hydroxytamoxifen combination therapy: a role for TGFbeta1. Int J Oncol 2003, 23(2):369-380.

8. El Etreby MF, Liang Y, Lewis RW: Induction of apoptosis by mifepristone and tamoxifen in human LNCaP prostate cancer cells in culture. Prostate 2000, 43(1):31-42.

9. Moe BT, Vereide AB, Orbo A, Jaeger R, Sager G: Levonorgestrel, medroxyprogesterone and progesterone cause a concentrationdependent reduction in endometrial cancer (Ishikawa) cell density, and high concentrations of progesterone and mifepristone act in synergy. Anticancer Research 2009, 29(4):1047-1052.

10. Moe BG, Vereide AB, Orbo A, Sager G: High concentrations of progesterone and mifepristone mutually reinforce cell cycle retardation and induction of apoptosis. Anticancer Research 2009, 29(4):1053-1058.

11. Fjelldal R, Moe BT, Orbo A, Sager G: MCF-7 cell apoptosis and cell cycle arrest: non-genomic effects of progesterone and mifepristone (RU-486). Anticancer Research 2010, 30(12):4835-4840.

12. Lin MF, Kawachi MH, Stallcup MR, Grunberg SM, Lin FF: Growth inhibition of androgen-insensitive human prostate carcinoma cells by a 19norsteroid derivative agent, mifepristone. Prostate 1995, 26(4):194-204

13. Goyeneche AA, Caron RW, Telleria CM: Mifepristone inhibits ovarian cancer cell growth in vitro and in vivo. Clin Cancer Res 2007. 13(11):3370-3379.

14. Freeburg EM, Goyeneche AA, Seidel EE, Telleria CM: Resistance to cisplatin does not affect sensitivity of human ovarian cancer cell lines to mifepristone cytotoxicity. Cancer Cell Int 2009, 9:4

15. Freeburg EM, Goyeneche AA, Telleria CM: Mifepristone abrogates repopulation of ovarian cancer cells in between courses of cisplatin treatment. Int J Oncol 2009, 34(3):743-755.

16. Fauvet $R$, Dufournet Etienne C, Poncelet $C$, Bringuier AF, Feldmann $G$, Darai $\mathrm{E}$ : Effects of progesterone and anti-progestin (mifepristone) treatment on proliferation and apoptosis of the human ovarian cancer cell line, OVCAR-3. Oncol Rep 2006, 15(4):743-748.

17. Rose FV, Barnea ER: Response of human ovarian carcinoma cell lines to antiprogestin mifepristone. Oncogene 1996, 12(5):999-1003.

18. Akahira J, Suzuki T, Ito K, Kaneko C, Darnel AD, Moriya T, Okamura K, Yaegashi N, Sasano H: Differential expression of progesterone receptor isoforms A and B in the normal ovary, and in benign, borderline, and malignant ovarian tumors. Jpn J Cancer Res 2002, 93(7):807-815.

19. Hamilton TC, Behrens BC, Louie KG, Ozols RF: Induction of progesterone receptor with 17 beta-estradiol in human ovarian cancer. J Clin Endocrinol Metab 1984, 59(3):561-563.
20. Keith Bechtel M, Bonavida B: Inhibitory effects of 17beta-estradiol and progesterone on ovarian carcinoma cell proliferation: a potential role for inducible nitric oxide synthase. Gynecol Oncol 2001, 82(1):127-138.

21. McDonnel AC, Murdoch WJ: High-dose progesterone inhibition of urokinase secretion and invasive activity by SKOV-3 ovarian carcinoma cells: evidence for a receptor-independent nongenomic effect on the plasma membrane. J Steroid Biochem Mol Biol 2001, 78(2):185-191.

22. Charles NJ, Thomas P, Lange CA: Expression of membrane progesterone receptors (mPR/PAQR) in ovarian cancer cells: implications for progesterone-induced signaling events. Horm Canc 2010, 1(4):167-176.

23. Peluso JJ, Gawkowska A, Liu X, Shioda T, Pru JK: Progesterone receptor membrane component-1 regulates the development and Cisplatin sensitivity of human ovarian tumors in athymic nude mice. Endocrinology 2009, 150(11):4846-4854.

24. Vermeulen K, Van Bockstaele DR, Berneman ZN: The cell cycle: a review of regulation, deregulation and therapeutic targets in cancer. Cell Prolif 2003, 36(3):131-149.

25. Mahajan DK, London SN: Mifepristone (RU486): a review. Fertil Steril 1997 68(6):967-976

26. Schneider CC, Gibb RK, Taylor DD, Wan T, Gercel-Taylor C: Inhibition of endometrial cancer cell lines by mifepristone (RU 486). J Soc Gynecol Investig 1998, 5(6):334-338.

27. Pinski J, Halmos G, Shirahige Y, Wittliff JL, Schally AV: Inhibition of growth of the human malignant glioma cell line (U87MG) by the steroid hormone antagonist RU486. J Clin Endocrinol Metab 1993, 77(5):1388-1392.

28. Lee WH: Characterization of a newly established malignant meningioma cell line of the human brain: IOMM-Lee. Neurosurgery 1990, 27(3):389-395, discussion 396

29. Wahab M, Al-Azzawi F: Meningioma and hormonal influences. Climacteric 2003, 6(4):285-292

30. Grunberg SM, Weiss MH, Russell CA, Spitz IM, Ahmadi J, Sadun A, SitrukWare R: Long-term administration of mifepristone (RU486): clinical tolerance during extended treatment of meningioma. Cancer Invest 2006, 24(8):727-733.

31. Spitz IM, Grunberg SM, Chabbert-Buffet N, Lindenberg T, Gelber H, SitrukWare R: Management of patients receiving long-term treatment with mifepristone. Fertil Steril 2005, 84(6):1719-1726.

32. Petz LN, Ziegler YS, Loven MA, Nardulli AM: Estrogen receptor alpha and activating protein-1 mediate estrogen responsiveness of the progesterone receptor gene in MCF-7 breast cancer cells. Endocrinology 2002, 143(12):4583-4591

33. Horwitz KB, Aiginger P, Kuttenn F, McGuire WL: Nuclear estrogen receptor release from antiestrogen suppression: amplified induction of progesterone receptor in MCF-7 human breast cancer cells. Endocrinology 1981, 108(5):1703-1709.

34. Vienonen A, Syvala $H$, Miettinen S, Tuohimaa P, Ylikomi T: Expression of progesterone receptor isoforms $A$ and $B$ is differentially regulated by estrogen in different breast cancer cell lines. I Steroid Biochem Mol Biol 2002, 80(3):307-313.

35. Thomas M, Monet JD: Combined effects of RU486 and tamoxifen on the growth and cell cycle phases of the MCF-7 cell line. J Clin Endocrinol Metab 1992, 75(3):865-870.

36. El Etreby MF, Liang Y, Wrenn RW, Schoenlein PV: Additive effect of mifepristone and tamoxifen on apoptotic pathways in MCF-7 human breast cancer cells. Breast Cancer Res Treat 1998, 51(2):149-168.

37. Gaddy VT, Barrett JT, Delk JN, Kallab AM, Porter AG, Schoenlein PV: Mifepristone induces growth arrest, caspase activation, and apoptosis of estrogen receptor-expressing, antiestrogen-resistant breast cancer cells. Clin Cancer Res 2004, 10(15):5215-5225.

38. Darro F, Cahen P, Vianna A, Decaestecker C, Nogaret JM, Leblond B, Chaboteaux C, Ramos C, Petein M, Budel V, Schoofs A, Pourrias B, Kiss R: Growth inhibition of human in vitro and mouse in vitro and in vivo mammary tumor models by retinoids in comparison with tamoxifen and the RU-486 anti-progestagen. Breast Cancer Res Treat 1998, 51(1):39-55.

39. El Etreby MF, Liang $Y$, Johnson MH, Lewis RW: Antitumor activity of mifepristone in the human LNCaP, LNCaP-C4, and LNCaP-C4-2 prostate cancer models in nude mice. Prostate 2000, 42(2):99-106.

40. Bonkhoff H, Fixemer T, Hunsicker I, Remberger K: Progesterone receptor expression in human prostate cancer: correlation with tumor progression. Prostate 2001, 48(4):285-291. 
41. Sasaki M, Tanaka Y, Perinchery G, Dharia A, Kotcherguina I, Fujimoto S, Dahiya R: Methylation and inactivation of estrogen, progesterone, and androgen receptors in prostate cancer. J Natl Cancer Inst 2002, 94(5):384-390.

42. Agoulnik IU, Krause WC, Bingman WE, Rahman HT, Amrikachi M, Ayala GE, Weigel NL: Repressors of androgen and progesterone receptor action. $J$ Biol Chem 2003, 278(33):31136-31148.

43. Rogatsky I, Hittelman AB, Pearce D, Garabedian MJ: Distinct glucocorticoid receptor transcriptional regulatory surfaces mediate the cytotoxic and cytostatic effects of glucocorticoids. Mol Cell Biol 1999, 19(7):5036-5049.

44. Horoszewicz JS, Leong SS, Kawinski E, Karr JP, Rosenthal H, Chu TM, Mirand EA, Murphy GP: LNCaP model of human prostatic carcinoma. Cancer Res 1983, 43(4):1809-1818.

45. Brooks SC, Locke ER, Soule HD: Estrogen receptor in a human cell line (MCF-7) from breast carcinoma. J Biol Chem 1973, 248(17):6251-6253.

46. Goyeneche AA, Seidel EE, Telleria CM: Growth inhibition induced by antiprogestins RU-38486, ORG-31710, and CDB-2914 in ovarian cancer cells involves inhibition of cyclin dependent kinase 2. Invest New Drugs 2011.

47. Baulieu EE: The antisteroid RU486: its cellular and molecular mode of action. Trends Endocrinol Metab 1991, 2(6):233-239.

48. Zhang S, Jonklaas J, Danielsen M: The glucocorticoid agonist activities of mifepristone (RU486) and progesterone are dependent on glucocorticoid receptor levels but not on EC50 values. Steroids 2007, 72(6-7):600-608.

49. Oakley RH, Jewell CM, Yudt MR, Bofetiado DM, Cidlowski JA: The dominant negative activity of the human glucocorticoid receptor beta isoform. Specificity and mechanisms of action. J Biol Chem 1999, 274(39):27857-27866

50. Taniguchi Y, Iwasaki Y, Tsugita M, Nishiyama M, Taguchi T, Okazaki M, Nakayama S, Kambayashi M, Hashimoto K, Terada Y: Glucocorticoid receptor-beta and receptor-gamma exert dominant negative effect on gene repression but not on gene induction. Endocrinology 2010, 151(7):3204-3213.

51. Yudt MR, Jewell CM, Bienstock RJ, Cidlowski JA: Molecular origins for the dominant negative function of human glucocorticoid receptor beta. $\mathrm{Mol}$ Cell Biol 2003, 23(12):4319-4330.

52. Lewis-Tuffin $L$, Jewell CM, Bienstock RJ, Collins JB, Cidlowski JA: Human glucocorticoid receptor beta binds RU-486 and is transcriptionally active. Mol Cell Biol 2007, 27(6):2266-2282.

53. Kino T, Manoli I, Kelkar S, Wang Y, Su YA, Chrousos GP: Glucocorticoid receptor (GR) beta has intrinsic, GRalpha-independent transcriptional activity. Biochem Biophys Res Commun 2009, 381(4):671-675.

54. Rohe HJ, Ahmed IS, Twist KE, Craven RJ: PGRMC1 (progesterone receptor membrane component 1): a targetable protein with multiple functions in steroid signaling, P450 activation and drug binding. Pharmacol Ther 2009, 121(1):14-19.

55. Gellersen B, Fernandes MS, Brosens JJ: Non-genomic progesterone actions in female reproduction. Hum Reprod Update 2009, 15(1):119-138.

56. Dressing GE, Goldberg JE, Charles NJ, Schwertfeger KL, Lange CA: Membrane progesterone receptor expression in mammalian tissues: $\mathrm{A}$ review of regulation and physiological implications. Steroids 2011, 76(12):11-17.

57. Thomas P, Pang Y, Dong J, Groenen P, Kelder J, de Vlieg J, Zhu Y, Tubbs C: Steroid and $G$ protein binding characteristics of the seatrout and human progestin membrane receptor alpha subtypes and their evolutionary origins. Endocrinology 2007, 148(2):705-718.

58. Peluso JJ, Liu X, Saunders MM, Claffey KP, Phoenix K: Regulation of ovarian cancer cell viability and sensitivity to cisplatin by progesterone receptor membrane component-1. J Clin Endocrinol Metab 2008, 93(5):1592-1599.

59. Smith JL, Kupchak BR, Garitaonandia I, Hoang LK, Maina AS, Regalla LM, Lyons TJ: Heterologous expression of human mPRalpha, mPRbeta and mPRgamma in yeast confirms their ability to function as membrane progesterone receptors. Steroids 2008, 73(11):1160-1173.

60. Parthasarathy S, Morales AJ, Murphy AA: Antioxidant: a new role for RU486 and related compounds. J Clin Invest 1994, 94(5):1990-1995.

61. Murphy AA, Zhou MH, Malkapuram S, Santanam N, Parthasarathy S, Sidell N: RU486-induced growth inhibition of human endometrial cells. Fertil Steril 2000, 74(5):1014-1019.
62. Roberts CP, Parthasarathy S, Gulati R, Horowitz I, Murphy AA: Effect of RU486 and related compounds on the proliferation of cultured macrophages. Am J Reprod Immunol 1995, 34(4):248-256.

63. Liberto M, Cobrinik D: Growth factor-dependent induction of p21(CIP1) by the green tea polyphenol, epigallocatechin gallate. Cancer Letters 2000, 154(2):151-161.

64. Liu M, Wikonkal NM, Brash DE: Induction of cyclin-dependent kinase inhibitors and $\mathrm{G}(1)$ prolongation by the chemopreventive agent $\mathrm{N}$ acetylcysteine. Carcinogenesis 1999, 20(9):1869-1872.

65. Dioufa N, Kassi E, Papavassiliou AG, Kiaris H: Atypical induction of the unfolded protein response by mifepristone. Endocrine 2010, 38(2):167-173.

\section{Pre-publication history}

The pre-publication history for this paper can be accessed here: http://www.biomedcentral.com/1471-2407/11/207/prepub

doi:10.1186/1471-2407-11-207

Cite this article as: Tieszen et al:: Antiprogestin mifepristone inhibits the growth of cancer cells of reproductive and non-reproductive origin regardless of progesterone receptor expression. BMC Cancer 2011 11:207.

\section{Submit your next manuscript to BioMed Central and take full advantage of:}

- Convenient online submission

- Thorough peer review

- No space constraints or color figure charges

- Immediate publication on acceptance

- Inclusion in PubMed, CAS, Scopus and Google Scholar

- Research which is freely available for redistribution 